\title{
Reply to Schurr and Gottwald
}

We reported an endoscopic full-thickness resection (EFTR) using the full thickness resection device (FTRD) at the appendiceal orifice with the appendix in situ requiring emergency surgery due to acute appendicitis [1]. The final histopathology showed appendicitis and residual serrated adenoma within the appendiceal stump but also, unexpectedly, a displaced adenoma fragment at the serosal surface of the cecum. We concluded that, given the transmural placement of the clip prior to snare resection, translocation of neoplastic tissue to the extraluminal site in cases of incomplete adenoma/carcinoma resection could be a concern [1]. Schurr and Gottwald argue that translocation of adenoma tissue through the cecal wall is unlikely since the FTRD clip is not per se acting transmurally, and that such displacement had most likely occurred during specimen preparation.

In reply to the first aspect, we would like to point out that, during laparoscopy, the clip was visible from the peritoneal side ( $>$ Fig. 1 , arrow), implicating a transmural injury. With regard to the second point, we naturally cannot rule out the possibility that a translocation of tissue had occurred during specimen processing. However, the specimen was fixed in formaldehyde solution for 24 hours before removing the clip for further preparation. Since formaldehyde is a strong cross-linker, it is perhaps not completely unlikely that the adenoma tissue had in fact been in place before the clip was removed. Thus, in contrast to Schurr and Gottwald, we still hold the opinion that the inadvertent placement of the FTRD clip through the neoplastic tissue might have led to translocation of an adenoma fragment to the extraluminal side of the colon. This is probably a rare event and its clinical significance is unclear. We nevertheless felt this observation worth reporting since we are dealing with a novel method, which undoubtedly is an excellent tool expanding the

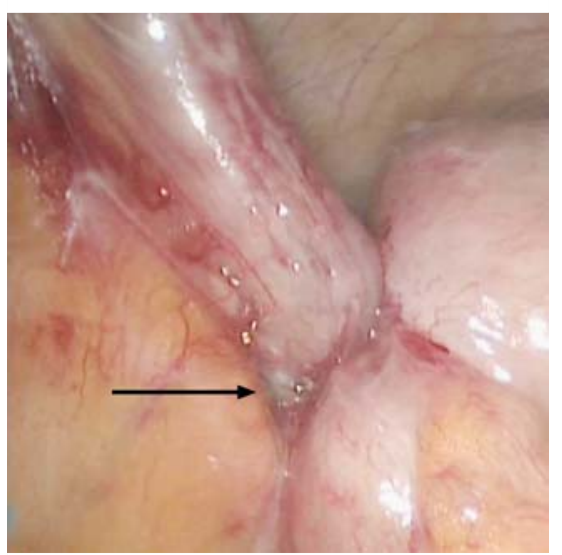

- Fig. 1 Clip (black arrow) visible from the peritoneal side during laparoscopy.

range of endoscopic resection techniques in the colon [2].

Finally, perforations occurring during endoscopic submucosal dissection (ESD) are a somewhat different matter. In contrast to EFTR where complete visual control of resection margins is not possible, tissue dissection during ESD is performed under direct visual control outside the neoplastic tissue [3] making a perforating cut through neoplastic tissue a very unlikely event.

\section{Competing interests}

None

The authors

Franz Ludwig Dumoulin ${ }^{1}$, Ralf Hildenbrand ${ }^{2}$, Bernd Sido ${ }^{3}$

1 Department of Medicine and Gastroenterology,

Gemeinschaftskrankenhaus Bonn, Bonn, Germany

2 Institute für Pathology Bonn-Duisdorf, Bonn, Germany

3 Department of General and Abdominal Surgery, Gemeinschaftskrankenhaus Bonn, Bonn, Germany
Corresponding author

Professor Dr. Franz Ludwig Dumoulin, MD PhD

Department of Medicine and

Gastroenterology,

Gemeinschaftskrankenhaus Bonn, Bonner

Talweg 4-6, D-53113 Bonn, Germany

Fax: +49-228-5081562

f.dumoulin@gk-bonn.de

d.gorris@gk-bonn.de

\section{References}

[1] Dumoulin FL, Gorris DG, Berger S et al. Fullthickness resection with an over-the-scope device: possible translocation of adenoma tissue in a case of an incomplete resection at the appendix. Endosc Int Open 2018; 6: E622 - E624

[2] Schmidt A, Beyna T, Schumacher B et al. Colonoscopic full-thickness resection using an over-the-scope device: a prospective multicentre study in various indications. Gut 2018; 67: 1280-1289

[3] Tanaka S, Kashida H, Saito Y et al. JGES guidelines for colorectal endoscopic submucosal dissection/endoscopic mucosal resection. Dig Endosc 2015; 27: 417-434

\section{Bibliography}

DOI http://dx.doi.org/10.1055/a-0732-5145

Endoscopy International Open 2018; 06: E1266

(c) Georg Thieme Verlag KG

Stuttgart · New York

ISSN 2364-3722

\section{(이 (1) $\odot \odot$}

